\title{
MUSEU TENENTE CAMARGO:TENTAME FRUSTRADO DO EXÉRCITO PARA CRIAÇÃO DE UM MUSEU CASA HISTÓRICA MILITAR
}

Ronaldo Zatta*

\begin{abstract}
Resumo
Este artigo tenta elaborar uma análise sobre uma a tentativa fracassada de criação de um Museu Casa Histórica Militar no sudoeste do Paraná por oficiais do exército brasileiro em 2005/2006. Tal museu pretendia ser denominado Museu Tenente Camargo, em homenagem a um "herói” militar das operações de contraguerrilha de 1965, no entanto, em 2010, a desautorização de funcionamento do museu foi expedida pelo escalão superior militar. Ações têm revelado o dissenso sobre como os militares lembram ou selecionam o que deve ser lembrando acerca de episódios relacionados ao período da Ditadura Militar brasileira, entretanto, a ação política institucional de criação de uma casa museal oportunizou visitações, devidamente orientadas, as quais se apresentaram com uma excelente oportunidade de educação patrimonial sobre a colonização regional e Ditadura Militar.
\end{abstract}

Palavras-chave: Museu. Exército. Ditadura.

* Mestre em História Regional pela Universidade de Passo Fundo (2009) e doutorando em História pela Universidade Federal do Paraná (UFPR). E-mail: ronaldozatta@yahoo.com.br 
Guardadas as devidas adaptações, este artigo contém parte da discussão erguida para elaboração da minha tese de Doutorado pelo Programa de Pós-Graduação em História da Universidade Federal do Paraná. Tal discussão tem possibilitado embasamento teórico para análise de uma experiência histórica ímpar da qual me percebi envolvido por ocasião da prestação de serviço militar ao Exército brasileiro em 2005/2006. Como dito, foi em setembro de 2006, enquanto prestava serviço militar na Subunidade Militar do Exército Brasileiro, sediado na cidade de Francisco BeltrãoPR, uma Organização Militar denominada como $16^{\circ}$ Esquadrão de Cavalaria Mecanizado, que, por ser acadêmico, fui designado, juntamente com outros dois estudantes de História, para compor a equipe de auxiliares do Curador do Museu Militar Tenente Camargo, durante a fase de criação, seleção e catalogação de acervo permanente daquele imóvel museal. Os esforços de criação daquela residência de lembranças, que por suas características está sendo referenciada como Museu Casa Histórica Militar, compõem um conjunto de ações de dois comandantes militares que colocaram em suas prioridades ações que retomaram um discurso do heroísmo militar de luta contra o comunismo durante a Ditadura Militar brasileira.

\section{O 'herói' militar da contraguerrilha que cedeu nome ao Museu Casa Histórica}

Em março de 1965, quando iria completar um ano do Regime Militar instaurado no Brasil, iniciou-se, no Estado do Rio Grande do Sul, uma tentativa fracassada de contragolpe comandada pelo ex-Coronel de Artilharia do Exército, Jeferson Cardim de Alencar Osório que tinha como seu principal assessor Albery Vieira dos Santos, ex-Sargento da Brigada Militar do Estado do Rio Grande do Sul. (MITCHELL, 2007, p. 51). Vinda do Uruguai, a guerrilha seguiu por algumas cidades dos três estados do sul do Brasil.

Existe a versão de que o ex-Sargento Albery, um dos exilados mais corajosos e radicais, procurou Brizola solicitando dinheiro para realizar a incursão armada e este não forneceu. Posteriormente, ao encontrar com Jeferson Cardim de Alencar Osório, nasceu o movimento. Cardim era parente remoto de Castelo Branco e ligado ao Partido Comunista Brasileiro (PCB), 
era um veterano militante de esquerda que despertava ódio aos militares do Exército porque quebrara a ética militar casando-se com a mulher de um companheiro e, em seguida, amasiando-se com sua enteada, ou seja, havia perdido o respeito do oficialato no meio militar (ARAUJO; CASTRO, 1997, p. 124).

Com rapidez, os dois começaram a se articular e, mesmo sem apoio de Brizola, conseguiram juntar mil dólares, três fuzis tchecos semiautomáticos e alguns revólveres. Arrumaram um caminhão e com vinte e três homens entraram no Brasil no dia 19 de março de 1965 (GASPARI, 2002, p. 192). Com tal efetivo e com a maioria de seus homens reunidos em território gaúcho surgiram as Forças Armadas de Libertação Nacional (FALN) (USTRA, 2006, p. 139-140). ${ }^{1}$

As FALN dominaram algumas unidades da Brigada Militar gaúcha, recolhendo armas e munições desses quartéis e fazendo breves proclamações revolucionárias pela rádio local (MITCHELL, 2007, p. 51). O grupo dirigiu-se, então, para o sudoeste do estado do Paraná, onde seus integrantes acabaram sendo aprisionados pela Organização Militar que viria a ser denominada por aquelas prisões como "Sentinela do Sudoeste", a

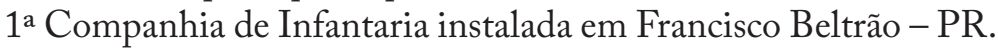

Os relatórios militares afirmam a versão de que no dia 27 de março de 1965, por volta das 11 horas, na região de Santa Lúcia, Município de Capitão Leônidas Marques - PR, ao pressentir a aproximação das tropas do Exército brasileiros oriundos da cidade de Francisco Beltrão, o grupo guerrilheiro realizou uma emboscada. ${ }^{2}$ Esse combate armado produziu uma vitima fatal, figura que mais tarde se transformaria em herói da Ditadura Militar: o $3^{\circ}$ Sargento Carlos Argemiro de Camargo. Camargo foi alvejado várias vezes ao desembarcar da viatura quando realizou contato com o grupo de Cardim (AUGUSTO, 2002, p. 169).

Entretanto, estudos recentes apontam que a situação pouco esclarecida da morte de Camargo pode ter encoberto algo inadmissível para os militares em tempos de repressão, a incompetência militar em combate. Há indícios de que o herói pode ter sido morto pelas armas dos próprios companheiros de pelotão durante o confronto armado, a "tese do tiro amigo" (ZATTA, 2013, p. 12).

Os guerrilheiros, após serem presos, foram conduzidos ao $1^{\circ}$ Batalhão de Fronteira, localizado em Foz do Iguaçu, julgados e condenados pela Justiça Militar, subordinada à $5^{\text {a }}$ Região Militar
1 A primeira ação armada contra o Regime Militar brasileiro em 1965 é conhecida por distintas designações, tais como "Coluna Cardim", "Operação Três Passos", "Forças Armadas de Libertação Nacional", "Guerrilha do Coronel Cardim" ou até mesmo ridicularizado sendo denominada "Exército Brancalione", fazendo referência à crônica medieval em que um grupo de maltrapilhos rouba alguns cavalos, autodenominase exército e parte em marcha utópica para conquista de um feudo imaginário.

2 Relatório do Tenente Lemos, transcrito no Livro Histórico da $3^{\text {a }}$ Companhia do $33^{\circ}$ Batalhão de Infantaria de Francisco Beltrão - PR, do Livro de Memórias do Tenente Camargo nas dependências do 16 $6^{\circ}$ Esquadrão de Cavalaria Mecanizado na cidade de Francisco Beltrão-PR. 
3 Para mais informações sobre a Operação Três Passos consultar a página da CNV. Disponível em: < http:// www.cnv.gov.br/index.php/ outros-destaques/497-cnvvai-ao-rio-grande-do-sulreconstruir-a-historia-doprimeiro-levante-armadocontra-a-ditadura-militar >

4 Art. $2^{\circ}$ do Decreto 4.207, a Medalha do Pacificador com Palma será concedida pelo Comandante do Exército aos militares e civis brasileiros que, em tempo de paz, no exercício de suas funções ou no cumprimento de missões de caráter militar, tenham se distinguido por atos pessoais de abnegação, coragem e bravura, com risco de vida.

5 Órgão getulista, criado em 1943, foi responsável pela colonização oficial do sudoeste do Paraná por meio do projeto de migração de descendes de origem europeia fixados anteriormente em Santa Catarina e Rio Grande do Sul.

6 A Praça Tenente Camargo localiza- se na alameda principal da área militar em Francisco Beltrão - PR foi e ainda continua sendo uma sala de visita e de cerimoniais militares. com sede em Curitiba - PR. Posteriormente, foram favorecidos pela Lei da Anistia, reparados monetariamente com indenizações da Comissão da Anistia e homenageados, em dezembro de 2014, pelo relatório da Comissão Nacional da Verdade. ${ }^{3}$

Carlos Argemiro de Camargo, no entanto, teve outro destino, para além de seu óbito em combate. Sua morte foi celebrada como ato extremo de heroísmo militar, sendo institucionalizado o culto fúnebre militar por quatro décadas como exemplo a ser seguido por militares e civis na luta contra o comunismo. Camargo foi promovido post mortem ao posto de $2^{\circ}$ Tenente e recebeu a mais alta honraria militar concedida pelas Forças Armadas por ato de bravura, a Medalha do Pacificador com Palma. ${ }^{4}$ Em seu culto, além de formaturas e cerimoniais militares e católicos, foram erguidos "lugares de memórias" como monumento, praça, rua, colégios, lápide e epitáfio, que o transformaram em uma das mais elaboradas construções simbólicas da Ditadura Militar brasileira. A última dessas construções foi a tentativa fracassada de criação do Museu Casa Histórica Militar Tenente Camargo em 2005/2006 (ZATTA; COSTA GAMA; RIPPEL, 2010, p. 105).

\section{Os esforços de criação do Museu Casa Histórica Tenente Camargo}

No ano de 2005, a organização militar de Francisco Beltrão estava sob o comando do Major de Cavalaria Marcílio Muniz da Silva e uma das prioridades daquele comandante era a construção do Museu Militar do $16^{\circ}$ Esquadrão de Cavalaria Mecanizado. Dentro da área militar do $16^{\circ}$ Esquadrão de Cavalaria Mecanizado encontrava-se - e, em partes, ainda encontra-se - um antigo conjunto arquitetônico em madeira de lei edificado no início da década de 1950 e que fora, inicialmente, utilizado como sede administrativa e conjunto habitacional de funcionários da Colônia Agrícola General Osório ${ }^{5}$ (Cango), passando, mais tarde, a compor a sede regional do - Instituto Nacional de Colonização e Reforma Agrária (Incra), e findando como depósitos do quartel de infantaria ali instalado na primeira metade do século passado.

Em meados de 2005, por ordem do Major Marcílio Muniz da Silva, uma dessas casas coloniais acabou sendo transportada para as proximidades da Praça Tenente Camargo ${ }^{6}$ com o intuito de ser instituído naquele local um Museu Casa Histórica. 
Figura 1. Solenidade Militar em frente ao Museu Casa Histórica Militar Tenente Camargo em 2006.

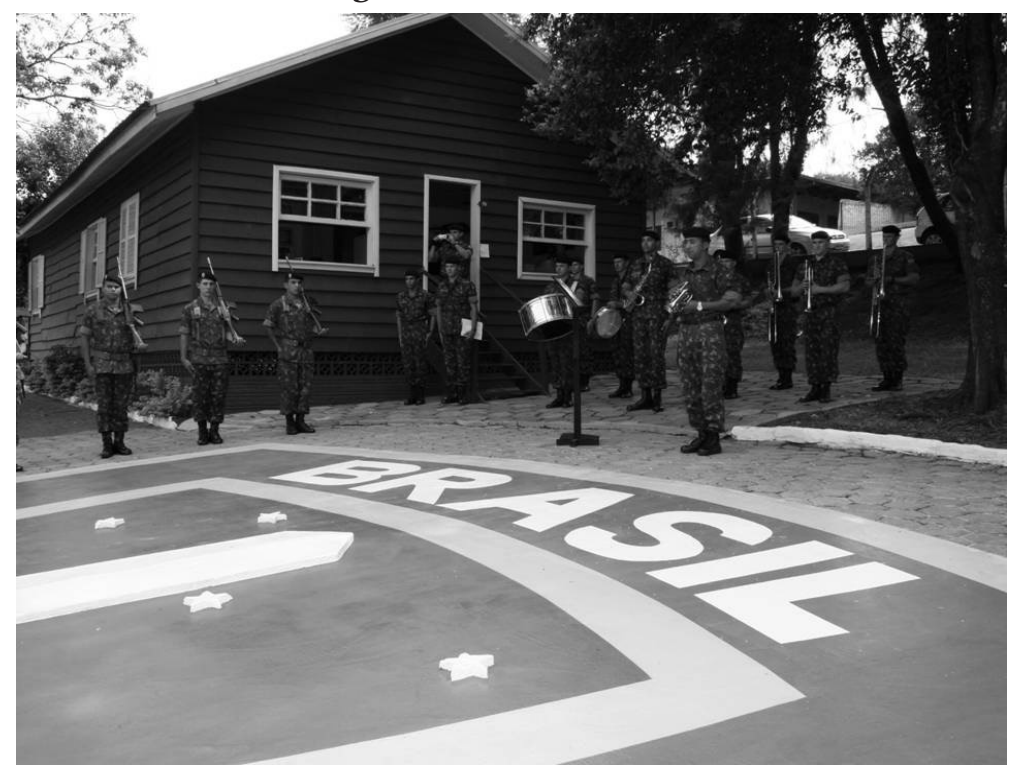

Fonte: Arquivo Fotográfico Militar e Sargento Reserva Remunerada João Olivo.

Devido o elevado estado de deterioração da madeira, causada pela umidade gerada pelo Rio Marrecas cujo curso é próximo às instalações da Cango, foram necessários alguns meses de trabalho do Pelotão de Obras para recuperar - com considerável sucesso em manter a originalidade arquitetônica - a construção de aproximadamente seis décadas de existência. Os trabalhos de restauração somente foram encerrados no fim de 2006, sendo, naquela oportunidade, realizada a solenidade de inauguração do museu do $16^{\circ}$ Esquadrão de Cavalaria Mecanizado, com o nome de Museu Militar Tenente Camargo, em 10 de novembro daquele ano com a apresentação de um acervo permanente.

Apesar da iniciativa de criação do Museu Militar Tenente Camargo partir do comandolocal,um projeto piloto com as mesmas alegorias foi realizado entre 2003 e 2004 pelo Departamento de Cultura da Prefeitura Municipal de Francisco Beltrão por meio do Projeto Memória. A retirada, transporte e restauração de outra casa das instalações da Cango foi empreendimento que culminou na criação do Museu do Colonizador, localizado dentro do Parque Jaime Cannet Junior. ${ }^{7}$

Em seguida, foi elaborada uma proposta de criação do Museu Militar pelo então tenente Rômulo Innocêncio Junior, graduado
7 A fundação do Museu do Colonizador compõe as ações de construção de monumentos públicos voltados à exaltação dos colonizadores, referenciados pela história oficial como pioneiros no sudoeste do Paraná. Esse esforço foi intensificado na última década por parte das autoridades regionais constituídas, abrindo precedência para discutir a relação da construção de monumentos de vínculos "pioneiristas" como uma forma de consolidação da memória oficial regional, considerando que o imaginário pode atuar como força reguladora da vida coletiva. O Projeto Memória da Prefeitura de Francisco BeltrãoPR fomenta a homenagem aos sulistas provenientes do Rio Grande do Sul e Santa Catarina com função de perpetuação do poder político constituído na região (ZATTA; RIPPEL; 2014 , p. 207). 
em História. Com a substituição do comandante anteriormente citado, essa proposta foi despachada um ano mais tarde pelo major Marcelo Lorenzini Zucco que sugeriu a denominação de "Museu Tenente Camargo" em homenagem ao herói militar da contraguerrilha de 1965.

Para Meneses, os bens culturais de uma casa-museu histórica podem e devem ser utilizados como fontes que permitam entender a "[...] sociedade que os reproduziu enquanto objetos históricos" (MENESES, 1994, p. 20). Dessa forma,

Num museu casa histórica, o documento (objeto/bem cultural) é o próprio espaço/cenário (o edifício), a coleção e o proprietário. Esses três referenciais devem sempre ser tomados em conta ao se pensar as ações de comunicação nesta tipologia de museu. Edifício, coleção e proprietário não estão desvinculados e, por isso, as relações estabelecidas entre eles favorecem a comunicação, permitem uma melhor interação com o espaço visitado e, fundamentalmente, a possibilidade de vir a perceber um determinado período histórico e a sociedade nele compreendida. (CABRAL, 2006, p. 1).

Comumente, a fundação de um Museu Casa Histórica está associada a um personagem histórico, isto é, a fundação é atrelada à assertiva de que tal personalidade residiu naquelas instalações, o que não é o caso no presente estudo. Sabe-se que as instalações da Cango foram construídas no início da década de 1950, e que o tenente Camargo fora transferido para aquela Unidade Militar em agosto de 1959, não sendo conclusivo afirmar que Camargo fora inquilino daquela edificação. Entretanto, tanto os militares como os funcionários da Cango e do Incra residiam dentro daquela área federal. Por fazer parte do grupo de militares casados, Camargo não convivia em alojamentos, sendo estes reservados aos milicianos solteiros, ele residia nas casas de madeiras que não eram suficientes para a instalação da tropa oriunda de Ponta Grossa - PR, sendo, muitas vezes, aquinhoadas entre duas famílias que dividiam as 'peças'(repartições) (REICKZIEGEL; ZATTA, 2012, p. 84 e 85).

Na percepção de Costa (2009, p. 30),

Os museus e seus objetos são universos de encantamento, curiosidade, admiração. Muitas vozes, muitas histórias. Memórias e esquecimentos. É necessário depreender enunciados implícitos entre efeitos de luz e sombra, entre vitrines que protegem, aprisionam e afastam. Dialogar, mas não só com o visível. Refratar, mas não só 
o exposto. Enfim, o desafio para a educação em museus é profundamente bakhtiniano: construir uma arena do pensar e não um templo para se admirar.

Nesse sentido, faz-se necessária a interpretação do acervo permanente do Museu Casa Histórica Tenente Camargo, destacando a presença, extremamente discreta, das passagens históricas em que aquela unidade apresentou em combate, incluindo o combate à guerrilha de 1965 , em que Carlos Argemiro de Camargo ${ }^{7}$ tombou o nome da casa. Além disso, é destacável também a ausência de armamentos e fardamentos.

\section{Figura 2. Pintura em Tela "Sargento Camargo"}

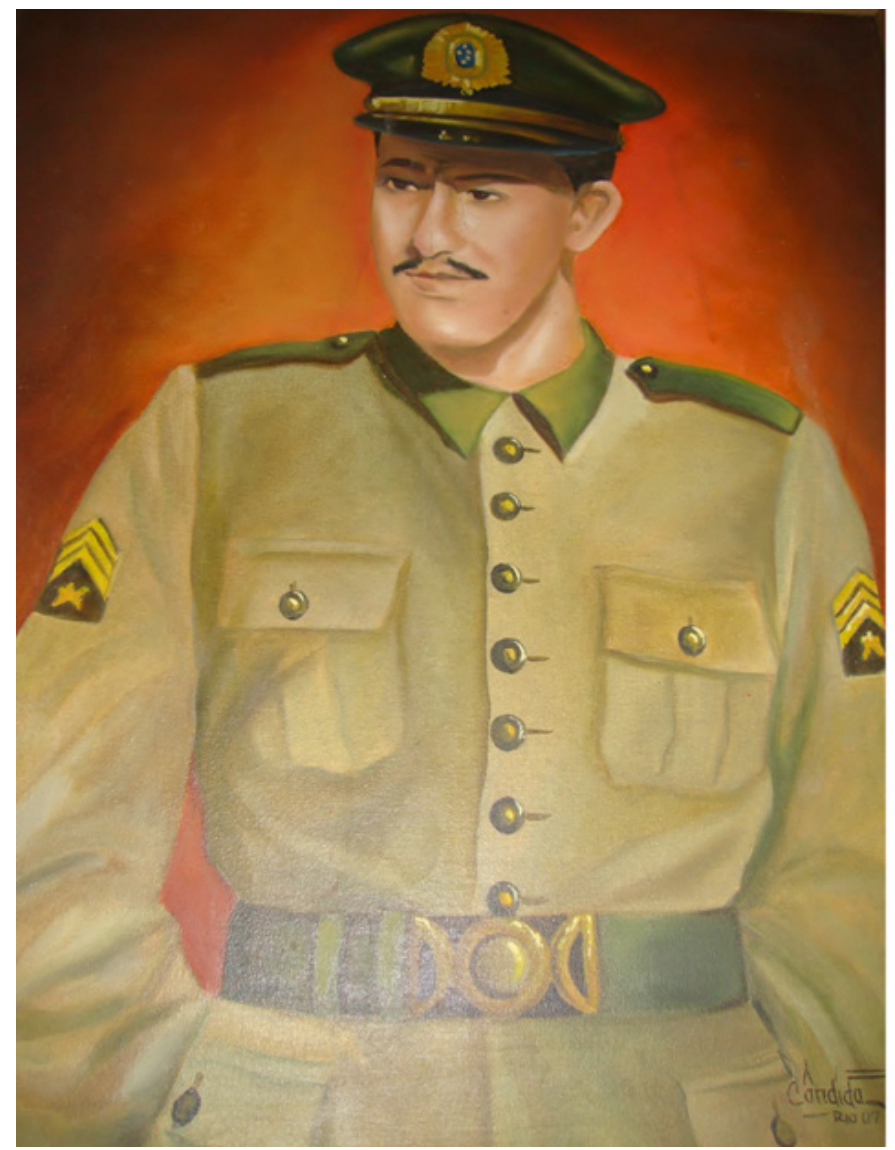

Fonte: Artista Cândida Ferrari - Rio de Janeiro - 2000.
7 Apenas duas peças do acervo da casa faziam referências diretas ao 'herói' e/ou à guerrilha: a pintura em tela do busto do herói e um livro de recortes com as noticias vinculadas à imprensa da época que retratava o episódio e o seu trágico desfecho.
O acervo, os pôsters e os quadros apresentavam, discretamente, a história de mais de 120 anos de existência 
$8 \mathrm{O} \quad 16^{\circ}$ Esquadrão de Cavalaria Mecanizado foi criado por uma Portaria Presidencial em 4 de fevereiro de 1984 no Estado de São Paulo.Com o nome de Corpo Provisório de Cavallaria, tinha a missão de combater a Revolução Federalista no Rio Grande do Sul. Em seu Livro de Registro Histórico foi manuscrita a presença em combate na Revolução Federalista, Guerra do Contestado, Revolução Paulista de 1924, Revolução de 1930, Revolução Constitucionalista de 1932, Segunda Guerra Mundial em 1944, Força de Paz em Angola 1994 e Força de Paz no Haiti 2010 ATTA; WERKHAUSER; 2012, p. 217). daquela unidade militar, bem como as suas participações nos diversos conflitos brasileiros. ${ }^{8}$ Por outro lado, esforçava-se em evidenciar os aspectos do cotidiano da tropa, instalação e fixação na região, além do convívio com a comunidade local em tempos de colonização.

\section{Figura 3. Aspectos do acervo permanente do Museu Casa Histórica Tenente Camargo}

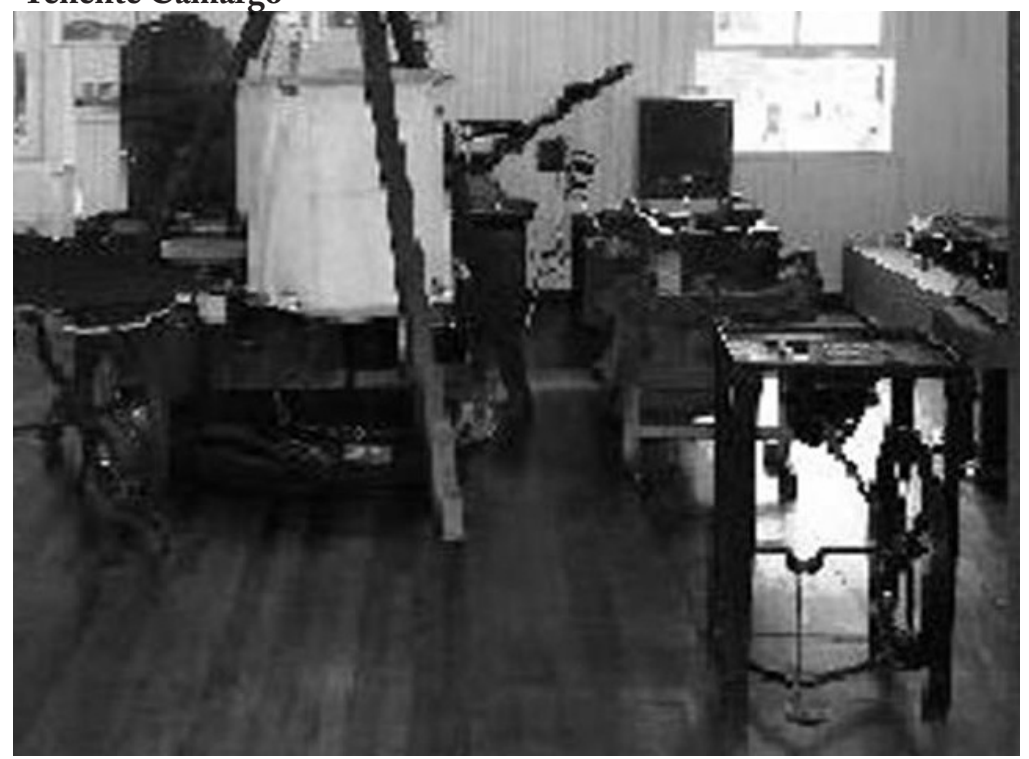

Fonte: Acervo do autor.

É evidente que todos os museus militares possuem viés ideológico, principalmente por tratarem de um grupo de identidade forte e distinta com funções celebrativas e evocativas. No entanto, as visitações nunca foram compreendidas como discurso de "doutrinadores de criancinhas". Primeiramente, pelo grau de instrução técnica do curador do museu que, mesmo sendo militar, tinha em seu currículo a graduação em História; em segundo, talvez o fator mais relevante, era a posição do comando militar local sobre as visitações, percebidas como atos de relações públicas desenvolvedoras do bom relacionamento com a comunidade. A análise do acervo do Museu Casa Histórica Tenente Camargo constituiu, enquanto manteve-se ativo, uma excelente aula sobre memória patrimonial, não só sobre o cotidiano militar, mas sobre a colonização regional, a Ditadura Militar e a criação dos heróis institucionalizados. 
Durante cinco anos, período que permaneceu aberto ao público externo ao aquartelamento, o Museu Casa Histórica Tenente Camargo recebeu frequentes visitações de escolas do ensino fundamental e médio, apresentando-se como uma rara oportunidade para os alunos locais de conhecerem acervos museais e tomarem parte de uma educação patrimonial.

Figura 4. Familiares do Tenente Camargo, sua sobrinha, a Professora Marinês Bósio. Ao fundo aspetos do acervo que recebia visitação de alunos do ensino fundamental e acadêmicos de História da Universidade Paranaense.

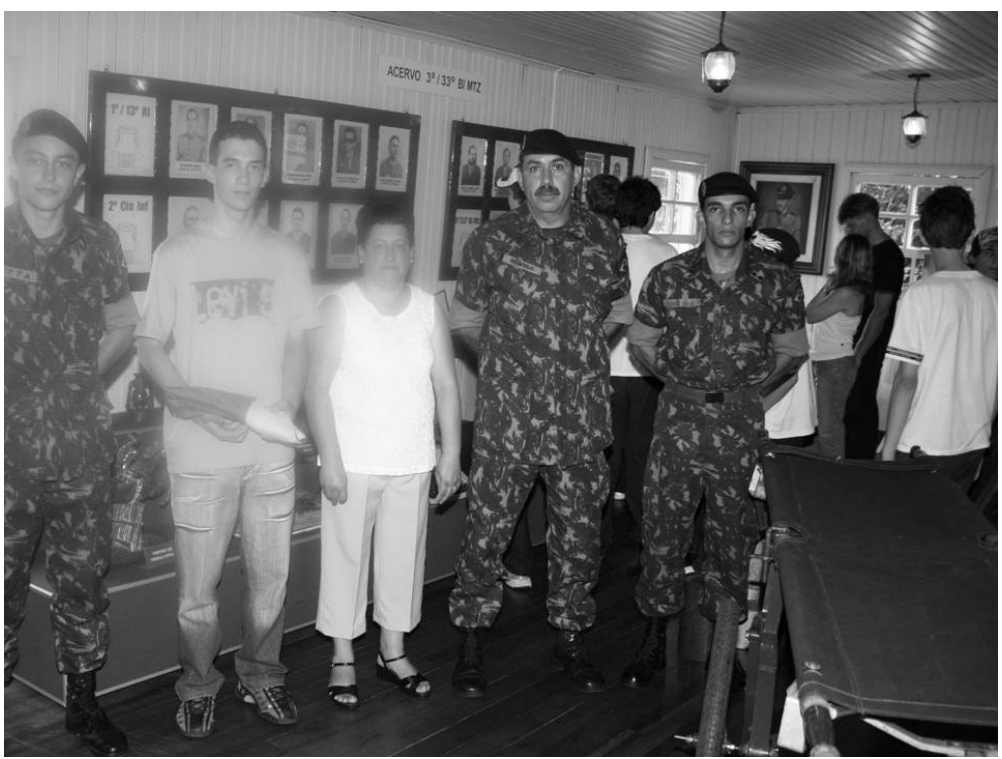

Fonte: Arquivo Pessoal do Fotógrafo Militar e Sargento da Reserva Remunerada João Olivo.

Geralmente, as visitas eram organizadas de forma que os alunos conhecessem as demais repartições do aquartelamento, exposições de viaturas e armamentos de dotação. Fazia parte do roteiro palestras sobre os aspectos cotidianos da tropa e rotina inerente à vida militar. $\mathrm{O}$ passeio terminava com um lanche no refeitório (rancho) servido pelos soldados.

\section{Considerações finais}

O contexto político da primeira década do século atual deixara entender que a criação do museu por aquela Organização 

luta contra o comunismo. Menos ainda, realçar a ideologia que regeu o ambiente militar durante a Guerra Fria, onde Camargo potencializou-se como 'exemplo' a ser seguido pelos militares e cidadãos, pois avalia-se que no discurso militar o 'herói' já cumprira sua função.

A hipótese mais provável que alavancara a tentativa de criação do Museu Casa Histórica Tenente Camargo são as metas de trabalho adotadas por dois comandantes que buscavam nutrir a memória militar local e valorizar a participação efetiva do Exército na resolução dos conflitos relativos à posse da terra em período de colonização. Além disso, a proximidade com as comemorações do Cinquentenário da Revolta dos Posseiros de 1957 ganhava destaque na imprensa, exigindo a elaboração de discursos e eleições de heróis pioneiros pelas instituições e poderes públicos. Nesse sentido, o Exército, como outros interessados, também precisava eleger os heróis do conturbado período de colonização fronteiriça (ZATTA; RIPPEL, 2013) mesmo que, para isso, tivessem que retomar o inventivo discurso ideológico de heroísmo militar que regeu as ações das Forças Armadas no século passado.

Sem motivação publicamente conhecida, o Museu Tenente Camargo não teve autorização de funcionamento expedida pelo Exército brasileiro e a, partir de 2010, teve suas instalações destinadas a secções do serviço burocrático militar, além de ter as características arquitetônicas dos anos 1950 severamente alteradas. O acervo foi desmobiliado e encaminhado para depósitos de quinquilharias ou exposto como suvenir em alguma repartição interna.

De forma contundente, pode-se rematar que a fracassada tentativa de criação de um Museu Casa Histórica Militar no sudoeste paranaense por oficiais militares do Exército brasileiro apresenta-se como uma finalidade política, mas que ofereceu uma ótima oportunidade de educação patrimonial para estudantes de História, servindo os seus objetos museais como mediadores de conhecimento sobre a Ditadura Militar e colonização, o que é raro naquela região.

A não autorização de funcionamento pelo escalão superior militar pode ser compreendida como divergência de posturas entre o oficialato, principalmente acerca das lembranças vinculadas à Ditadura. Certo é que o fechamento do museu, a dispersão de seu 
acervo e alteração das características originais daquela construção histórica é uma perda da memória patrimonial não só para a instituição militar, mas também para a comunidade local. Fora dos círculos hierárquicos, segue certo descrédito em relação à história oficial daquela instituição, um preço pago pelo Exército brasileiro pela falta de assessoria histórica na construção de uma narrativa sobre a sua trajetória política.

\section{Referências}

ARAÚJO, Maria Celina de; CASTRO, Celso (Orgs.). Ernesto Geisel. Rio de Janeiro: Editora FGV, 1997.

AUGUSTO, Agnaldo Del Nero. A grande mentira. Rio de Janeiro: Bibliex, 2002.

BRASIL. Decreto N. 4.207, de 23 de Abril de 2002. Dispõe sobre a medalha do pacificador e dá outras providências.

CABRAL, Magaly. Educação em Museus Casas Históricas, p.16, 2006, p. 1. Disponível em: <http:/www.casaruibarbosa.gov.br/ paracriancas/interna.php?ID_M=30>.Acesso em: $11 \mathrm{dez} .2014$.

COSTA, Carina Martins. Uma casa e seus segredos: a formação de olhares sobre o Museu Mariano Procópio. Mosaico, Rio de Janeiro, v. 1, p. 010-30, 2009.

COMISSÃO NACIONAL DA VERDADE. CNV vai ao RS reconstruir a história do primeiro levante armado contra a Ditadura Militar. Disponível em: <http://www.cnv.gov.br/index.php/outrosdestaques/497-cnv-vai-ao-rio-grande-do-sul-reconstruir-a-historiado-primeiro-levante-armado-contra-a-ditadura-militar $>$. Acesso em: 19 dez. 2014.

FERRARI, Cândida. Retrato-Sargento Camargo. 2000. 1 original de arte, óleo sobre tela, $50 \mathrm{~cm}$ x $40 \mathrm{~cm}$. Pavilhão de Comando do $16^{\circ}$ Esquadrão de Cavalaria Mecanizado.

GASPARI, Elio. A ditadura envergonhada. São Paulo: Cia das Letras, 2002.

LIVRO de memórias sobre o Tenente Camargo. $16^{\circ}$ Esquadrão de Cavalaria Mecanizado.

MENESES, Ulpiano T. Bezerra de. Do teatro da memória ao laboratório 
da História: a exposição museológica e o conhecimento histórico. In: Anais do Museu Paulista - História e Cultura Material, vol. 2. São Paulo: Museu Paulista/Universidade de São Paulo, 1994, p. 9-41.

MITCHELL, José. Segredos à direita e à esquerda na ditadura militar. Porto Alegre: RBS Publicações, 2007.

REICKZIEGEL, Ana Luiza Setti; ZATTA, Ronaldo. Vigias e compartes: o Exército brasileiro no sudoeste paranaense. In: REICKZIEGEL, Ana Luiza Setti et al. (Orgs.). O fuzil e a enxada: História Militar do sudoeste paranaense. Francisco Beltrão: Grafisul Gráfica e Editora, 2012, p. 75-96.

RELATÓRIO do Tenente Lemos Transcrito no Livro Histórico da

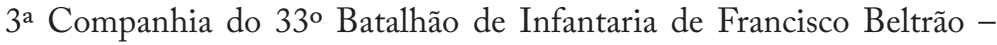
PR, do Livro de Memórias do Tenente Camargo que se encontra no Museu Militar Tenente Camargo nas dependências do $16^{\circ}$ Esquadrão de Cavalaria Mecanizado na cidade de Francisco Beltrão-PR.

USTRA, Carlos Alberto Brilhante. A verdade sufocada: a história que a esquerda não quer que o Brasil conheça. Brasília: Editora Ser, 2006.

ZATTA, Ronaldo. A Análise Do Discurso Na Narrativa De Um Cerimonial Militar: O Caso Tenente Camargo. Revista Semina, Passo Fundo, vol. 12, n. 1, 2013, pp.1-19.

ZATTA, Ronaldo; COSTA GAMA, Josué; RIPPEL, Leomar. Tenente Camargo: estudo de memória sobre a institucionalização de um "herói" militar. Francisco Beltrão: Editora Grafisul, 2010.

ZATTA. Ronaldo; RIPPEL, Leomar. A eleição de “heróis” pioneiros na revolta dos posseiros de 1957 no sudoeste do Paraná”. Revista IDeAS - Interfaces em Desenvolvimento, Agricultura e Sociedade, Rio de Janeiro - RJ, v. 7, n. 1, p. 43-68, 2013.

ZATTA, Ronaldo, RIPPEL, Leomar. Sedimentando memórias e construíndo imaginários: o poder simbólico na edificação de monumentos aos pioneiros no sudoeste do Paraná. Cadernos do CEOM (Unochapecó), v. 27, p. 207-225, 2014.

ZATTA, Ronaldo; WERKHAUSER, Carla. Milicos e matungos: Narrativa histórica do $16^{\circ}$ Esquadrão de Cavalaria Mecanizado. In: Ana Luiza Setti Reickziegel; Ronaldo Zatta; Leomar Rippel; Nelci Zatta. (Org.). O fuzil e a enxada: História Militar do Sudoeste paranaense. Francisco Beltrão: Grafisul Gráfica e Editora, 2012, pp. 209-228. 


\title{
TENENT CAMARGO MUSEUM: TENTAME ARMY FRUSTRATED FOR ESTABLISHMENT OF A MUSEUM HOUSE MILITARY HISTORY
}

\begin{abstract}
This article attempts to prepare an analysis on a the failed attempt to create a Historic House Military Museum in southwestern Paraná by the Brazilian army officers in 2005/2006 was intended to be named Lieutenant Camargo Museum in honor of a "hero " of military operations counterinsurgency 1965; and, the consequent disempowerment of operation of the museum issued by the military upper echelon in 2010. Actions that have shown dissent about the military remember, or select what should be remembering on episodes of the Brazilian military dictatorship. However, the institutional political action of creating a museum house provided an opportunity visitations, which where were properly targeted, presented with an excellent opportunity to heritage education on regional colonization and military dictatorship .
\end{abstract}

Keywords: Museum. Army. Dictatorship. 